\title{
Metabolite Alterations in Basal Ganglia Associated with Methamphetamine-related Psychiatric Symptoms: A Proton MRS Study
}

Yoshimoto Sekine, M.D., Ph.D., Yoshio Minabe, M.D., Ph.D., Masayoshi Kawai, M.D., Katsuaki Suzuki, M.D., Ph.D., Masaomi Iyo, M.D., Ph.D., Haruo Isoda, M.D., Ph.D., Harumi Sakahara, M.D., Ph.D., Charles R. Ashby Jr., Ph.D., Nori Takei, M.D., Ph.D., M.Sc., and Norio Mori, M.D., Ph.D.

Following the chronic use of methamphetamine, some individuals experience psychosis and anxiety. One reason may be the persistence of metabolite abnormalities in the brain of currently abstinent former methamphetamine users. In this study, N-acetylaspartate (NAA), creatine plus phosphocreatine $(\mathrm{Cr}+\mathrm{PCr})$, and choline-containing compound (Cho) levels were measured in the left and right basal ganglia using proton magnetic resonance spectroscopy (MRS) in 13 abstinent methamphetamine users and 11 healthy comparison subjects with no history of illicit drug use. The methamphetamine users showed a significantly reduced $\mathrm{Cr}+\mathrm{PCr} /$ Cho ratio in the bilateral basal ganglia compared with the healthy comparison subjects.
Furthermore, the reduction in the $\mathrm{Cr}+\mathrm{PCr} /$ Cho ratio was significantly correlated with the duration of methamphetamine use and with the severity of residual psychiatric symptoms. NAA/Cho ratios in the bilateral basal ganglia did not significantly differ between methamphetamine users and comparison subjects. These findings suggest that protracted use of methamphetamine may cause metabolite alterations in the basal ganglia. Furthermore, residual psychiatric symptoms may be attributable to the metabolite alterations in the basal ganglia. [Neuropsychopharmacology 27:453-461, 2002] (C) 2002 American College of Neuropsychopharmacology. Published by Elsevier Science Inc.
From the Department of Psychiatry and Neurology, Hamamatsu University School of Medicine, Hamamatsu, Japan (YS, YM, MK, KS, NT, NM), Department of Psychiatry, Graduate School of Medicine, Chiba University, Chiba, Japan (MI), Department of Radiology, Hamamatsu University School of Medicine, Hamamatsu, Japan (HI, HS), Department of Pharmaceutical Sciences, College of Pharmacy, St. John's University, NY (CRA), Institute of Psychiatry, London, UK (NT), Stanley Foundation Research Center in Japan, Hamamatsu, Japan (NT).

Address correspondence to: Yoshio Minabe, M.D., Ph.D., Department of Psychiatry and Neurology, Hamamatsu University School of Medicine, 1-20-1 Handayama, Hamamatsu, 431-3192 Shizuoka, Japan. Tel: +81 53435 2295; Fax: +81 53435 3621; E-mail: minabe@ hama-med.ac.jp

Received July 24, 2001; revised February 19, 2002; accepted February 28, 2002.

Online publication: 3/5/02 at www.acnp.org/citations/ Npp030502262.
KEY WORDS: Methamphetamine; Basal ganglia; Proton magnetic resonance spectroscopy

The number of abusers of the highly addictive drug methamphetamine has risen substantially worldwide and this has raised important concerns (Woolverton et al. 1984; Baberg et al. 1996; Shaw 1999). For example, chronic methamphetamine users show psychosis and anxiety following intoxication and withdrawal (Seivewright 2000). In addition, in some individuals, these psychiatric states may be present for months or even years after cessation of methamphetamine use (Sato et al. 1992; Iwanami et al. 1994; Buffenstein et al. 1999; Iyo et al. 1999). Although there are growing clinical observations on the neurotoxicology of chronic methamphetamine use, the mechanism by which the residual psychiatric problems arise from chronic methamphetamine 
use remains unknown. In rodents and baboons, methamphetamine has been shown to be toxic to dopaminergic and serotonergic neurons (Nakayama et al. 1993; Villemagne et al. 1998; Kokoshka et al. 1998). These neurotoxic effects include decreased concentrations of dopamine and serotonin in the brain and a reduction of dopamine and serotonin transporters, as well as loss of ATP and mitochondrial dysfunction in dopaminergic neurons (Chan et al. 1994; Burrows et al. 2000; Lotharius and O'Malley 2001). Human positron emission tomography (PET) studies have reported a significant reduction of dopamine transporter density in methamphetamine users (McCann et al. 1998; Volkow et al. 2001), and that the reduction observed in methamphetamine users is associated with psychomotor impairment (Volkow et al. 2001). Recently, we have also found that the dopamine transporter density in methamphetamine users is inversely related to the length of methamphetamine use and the magnitude of psychiatric symptoms, including psychotic symptoms (Sekine et al. 2001).

In vivo proton magnetic resonance spectroscopy $\left({ }^{1} \mathrm{H}\right.$ MRS) and its variant ${ }^{1} \mathrm{H}$ MRS techniques provide insight into the metabolism of several endogenous brain chemicals (Miller 1991; Jackson 1992). A recent ${ }^{1} \mathrm{H}$ MRS study showed evidence for long-term metabolite alterations in currently abstinent former methamphetamine users, that is, reduced concentration of both $\mathrm{N}$-acetylaspartate (NAA) and creatine plus phosphocreatine $(\mathrm{Cr}+\mathrm{PCr})$ in the right basal ganglia (Ernst et al. 2000). However, it is unclear whether these abnormalities detected by ${ }^{1} \mathrm{H}$ MRS are related to psychiatric symptoms that are frequently observed in abstinent methamphetamine users.

In this study, we investigated changes of the chemistry in the basal ganglia of abstinent methamphetamine users by ${ }^{1} \mathrm{H}$ MRS, and examined any relationship between the changes and clinical characteristics.

\section{METHODS}

\section{Subjects}

Thirteen methamphetamine users and 11 healthy comparison subjects who never used methamphetamine were recruited for our comprehensive research project on methamphetamine-related psychiatric disorders (Sekine et al. 2001). Subjects were excluded if they were seropositive for HIV-1, or had a history of head trauma with loss of consciousness. All participants showed no signs of parkinsonism or other neurological abnormalities. In addition, all participants had no history of seizures, dyskinesia or coma, which may be observed during intoxication after the use of high doses of methamphetamine. Subjects were screened for the use of nicotine, alcohol and other drugs with the non- patient version of the Structured Clinical Interview for DSM-IV (SCID) (First et al. 1996). Both groups of the comparison subjects and methamphetamine users showed similar habits of occasional smoking and drinking, with no subjects matching either the nicotine- or the alcohol-related criteria. The comparison subjects had no experience of use of any kind of illicit drugs, and had no history of Axis I disorders according to DSM-IV, including substance-related disorders. Furthermore, none of the methamphetamine users used any other drugs (i.e., they were mono-drug users) and had had no history of DSM-IV Axis I disorders before the use of methamphetamine. These evaluations were made with SCID. The methamphetamine users were recruited from the Hamamatsu University Hospital and Hattori Mental Hospital.

In order to increase the accuracy of the patient profiles, detailed information on methamphetamine use and history of psychiatric symptoms in methamphetamine users were obtained through interviews with the user and his/her family members, and by referral to patient medical records. The period of methamphetamine use was defined as the duration between initial use and last use. If there were intervals of abstinence longer than one month during the duration of methamphetamine use as defined, these intervals were subtracted from the total length of the use. The period of abstinence from methamphetamine use was defined as the duration between the day of last use of methamphetamine and the day of ${ }^{1} \mathrm{H}$ MRS examination. Absence of recent use of methamphetamine was ascertained by urinary drug screening tests.

Psychiatric symptoms were evaluated on the Brief Psychiatric Rating Scale (BPRS) (Overall and Gorham 1962); the assessment was conducted by a trained research psychiatrist (Y.S.) blind to the ${ }^{1} \mathrm{H}$ MRS data. In addition to the total BPRS score, we also obtained scores on the positive symptom BPRS subscale (Mohr et al. 1998) (i.e., conceptual disorganization, tension, mannerism and posturing, grandiosity, hostility, suspiciousness, hallucinatory behavior, uncooperativeness, unusual thought, and excitement) and on the negative symptom BPRS subscale (Mohr et al. 1998) (i.e., emotional withdrawal, motor retardation, blunted affect, and disorientation). After a complete description of the study to the subjects, written informed consent was obtained before study entry, in compliance with the procedures of the Ethics Committee of the Hamamatsu University School of Medicine.

\section{Image Acquisition}

MRS studies were performed at the Hamamatsu University Hospital. All studies were performed with a 1.5$\mathrm{T}$ whole body MR scanner (Signa Horizon; General Electric Medical Systems, Milwaukee, WI) equipped 
with self-shielded gradient coils. A quadrature, MRI bird-cage coil (transmit/ receive) was used in all studies. The localized MR spectra were recorded using the point-resolved spatially localized spectroscopy (PRESS) sequence from the bilateral basal ganglia. The RF transmitter frequency was centered at the water resonance frequency $(63.88 \mathrm{MHz})$. A $90^{\circ}$ flip angle was determined by varying the $R F$ amplifier gain until a maximal signal consistent with good slice profile was obtained. The B0 shim on the $27 \mathrm{ml}$ cubic excited volume was optimized using linear shims to a full-width at half-maximum (FWHM) of $<6.4 \mathrm{~Hz}$. Voxel size was $8 \mathrm{~cm}^{3}(2 \times$ $2 \times 2 \mathrm{~cm}$ ). To establish the voxel of interest (VOI) on MRS, scout views in proton density images were obtained vertically in the Z-axis (Figure 1). Proton density images were acquired because the gray matter contrasts well with white matter in the imaging.

After the location of the VOI had been verified by localized MRI, the magnetic field in the VOI was optimized by means of the water signal to establish a line width of $<$ $3 \mathrm{~Hz}$. The acquisition parameters were: repetition time (TR), $1500 \mathrm{~ms}$; echo time (TE), $40 \mathrm{~ms}$; and acquisition time, $3 \mathrm{~min} 42 \mathrm{~s}$. Peaks of NAA $\left(\mathrm{CH}_{3}, 2.0 \mathrm{ppm}\right), \mathrm{Cr}+\mathrm{PCr}$
$\left(\mathrm{N}-\mathrm{CH}_{3}, 3.0 \mathrm{ppm}\right)$, and choline-containing compound (Cho) $\left(\mathrm{N}-\left(\mathrm{CH}_{3}\right)_{3}, 3.2 \mathrm{ppm}\right)$ were obtained. Data processing was performed using PROBE/SV-Quant tool (General Electric Medical Systems, Milwaukee, WI) which employs a standard nonlinear least-squares algorithm for fitting the observed data. The metabolite ratios were calculated from the fitted peak integrals in the resulting spectra with a method of automatic metabolite peak measurement (Kreis et al. 1991; Webb et al. 1994). Representative spectra for the right basal ganglia region of a comparison subject and a methamphetamine user are shown in Figure 2. The ratios of NAA/Cr+PCr, NAA/Cho, and $\mathrm{Cr}+\mathrm{PCr} / \mathrm{Cho}$ in the methamphetamine users were compared with those of the comparison subjects.

It should be noted that we were unable to exclude potential cerebrospinal fluid (CSF) contamination. All measurements were determined by reference to a standard neuroanatomic atlas (Daniels et al. 1987), and care was taken to minimize CSF. However, measurement of tissue water signal from the voxel was too variable owing to tissue/ventricle artifact to be used to calculate absolute concentrations of metabolites. Thus, we only reported the metabolite ratios.

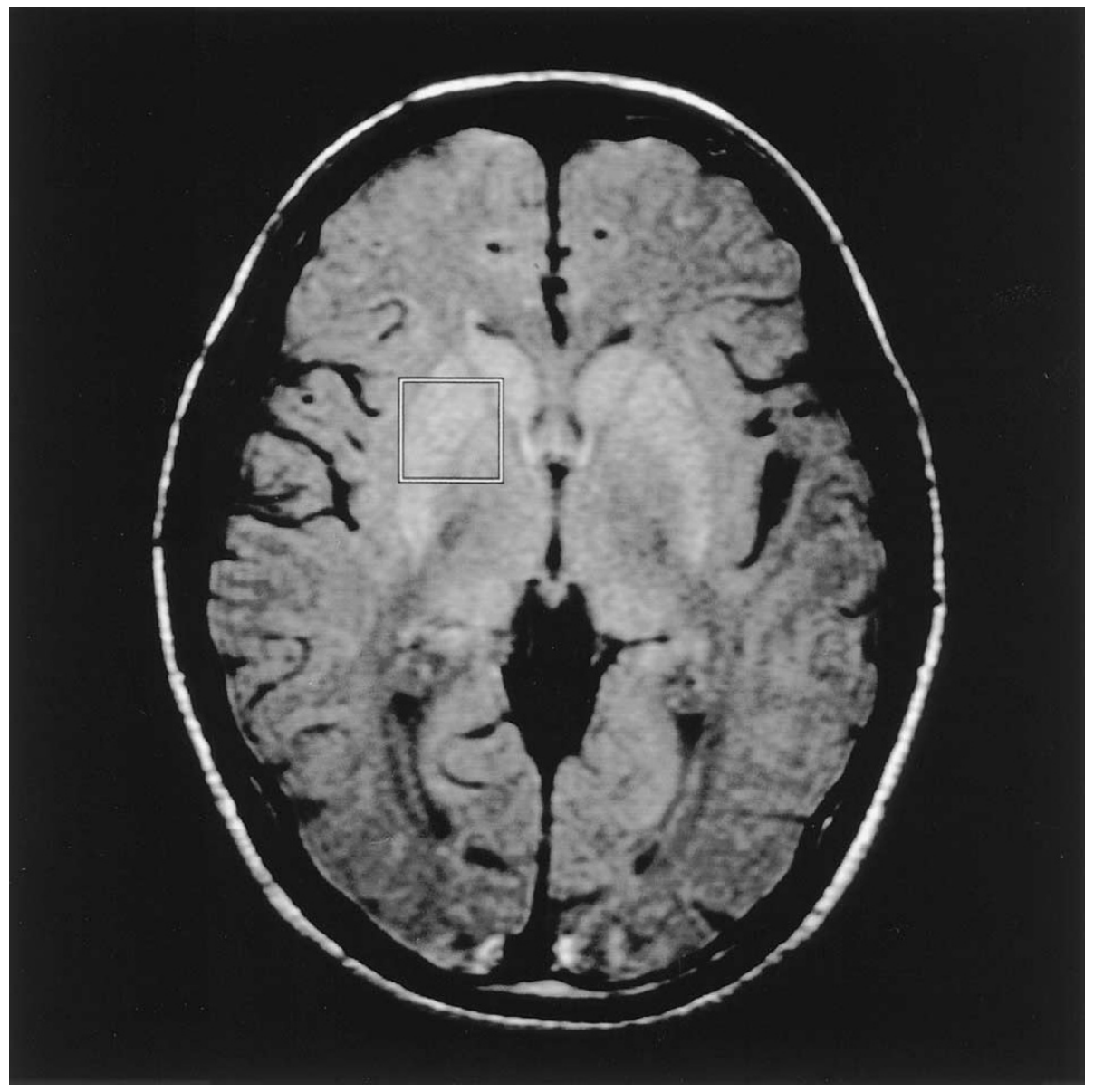

Figure 1. Axial slice proton density MRI showing the typical locations of the MRS voxel. The left side of the figure is the right side of brain. 

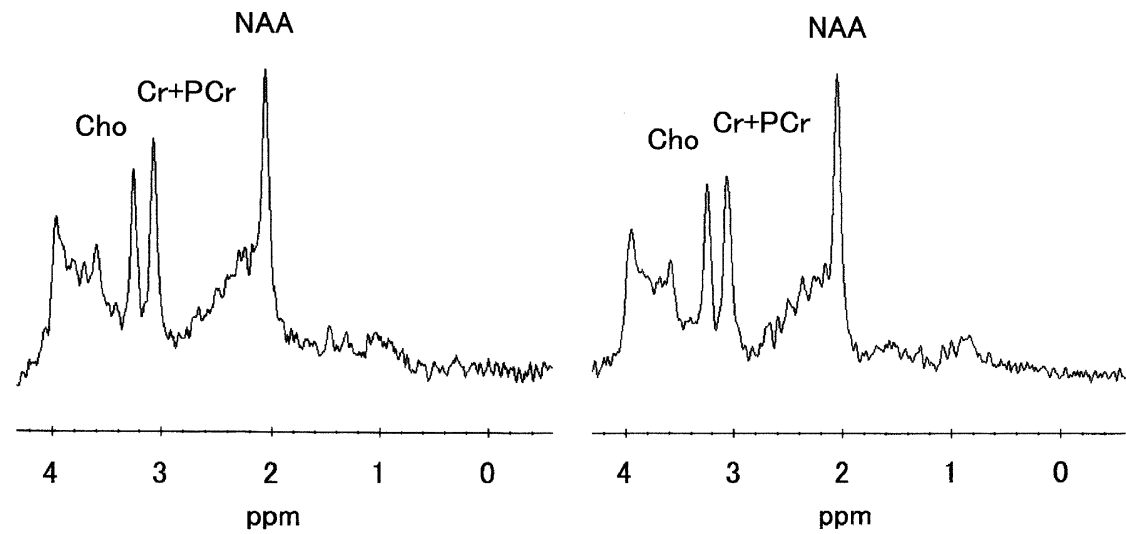

Figure 2. Proton MRS spectra for the right basal ganglia region of a comparison subject (left panel) and a methamphetamine user (right panel). Cho $=$ choline-containing compounds; $\mathrm{CR}+$ $\mathrm{PCr}=$ creatine plus phosphocreatine; $\mathrm{NAA}=\mathrm{N}$-acetylaspartate

\section{Statistical Analysis}

For comparison of the mean values of the metabolite ratios between methamphetamine users and comparison subjects, the Student's $t$-test was used. Correlations between the metabolite ratios and each of clinical parameters, including duration of methamphetamine use, duration of abstinence, and BPRS score, were evaluated using Pearson's correlation coefficient. Statistical significance was set at $p<.05$. We measured metabolite ratios in the basal ganglia on both the left and right sides in each subject. The values measured in each of the hemispheres were naturally not independent within the same individual, and separate analyses of the ratios as measured on each side increases the risk of a Type I error related to multiple testing. To avoid such errors, we used repeated measures analysis of variance (ANOVA) in which repeated measures were the left and right metabolite ratios.

\section{RESULTS}

The demographic characteristics of methamphetamine users and comparison subjects are shown in Table 1. No significant difference was observed in the distribution of age or sex between methamphetamine users and comparison subjects. None of the methamphetamine users had a history of psychiatric symptoms before the use of methamphetamine, and none showed negative symptoms during the present examination. None of the methamphetamine users were taking neuroleptics at the time of ${ }^{1} \mathrm{H}$ MRS study, although two of them had previously received treatment with neuroleptics for methamphetamine psychosis.

The values for metabolite ratios in the left and right basal ganglia are shown in Table 2. Statistical analyses (repeated measures ANOVA) indicated that there was no significant interaction of 'group' and 'laterality (left vs. right)' in any of the three metabolite ratios, suggesting that any differences in the ratios between the two groups were similar in the left and right basal ganglia.
There was no significant difference in the NAA/ $\mathrm{Cr}+\mathrm{PCr}$ or NAA/Cho ratio between the two groups (NAA/Cr+PCr: $\mathrm{F}=0.63, \mathrm{df}=1,22, p=.44$; NAA/Cho: $\mathrm{F}=1.71, \mathrm{df}=1,22, p=.20$ ), while methamphetamine users had significantly lower $\mathrm{Cr}+\mathrm{PCr} / \mathrm{Cho}$ ratios than comparison subjects $(\mathrm{F}=7.12, \mathrm{df}=1,22, p=.014)$.

For the methamphetamine users, there were significant correlations between the clinical data and the values of $\mathrm{Cr}+\mathrm{PCr} / \mathrm{Cho}$ ratios in the left and right basal ganglia (Figure 3). However, there was no significant correlation between the clinical measures and the $\mathrm{NAA} / \mathrm{Cr}+\mathrm{PCr}$ or NAA/Cho ratios (data not shown). There was a significant negative correlation between the $\mathrm{Cr}+\mathrm{PCr} / \mathrm{Cho}$ ratio and the duration of methamphetamine use in the basal ganglia bilaterally (left: $\mathrm{r}=$ $-0.76, \mathrm{df}=12, p=.002$; right: $\mathrm{r}=-0.60, \mathrm{df}=12, p=$ .03). Furthermore, there was a significant negative correlation between the $\mathrm{Cr}+\mathrm{PCr} / \mathrm{Cho}$ ratios and the scores on the BPRS subscale for positive symptoms in the both left and right basal ganglia (left: $\mathrm{r}=-0.66, \mathrm{df}=12, p=$ .01 ; right: $\mathrm{r}=-0.78, \mathrm{df}=12, p=.002)$. However, visual inspection of Figure 3 shows that these significant correlations could be influenced by a single subject; in fact, standard procedures with the box-and-whisker plot reveal one subject to be an outlier, with duration of methamphetamine use of 10 years in the upper panels of Figure 3 and with the highest positive symptom subscore on BPRS in the lower panels of Figure 3. Thus, we eliminated this subject and repeated the analysis. The significant negative correlation between the $\mathrm{Cr}+\mathrm{PCr} / \mathrm{Cho}$ ratio and the duration of methamphetamine use in the left basal ganglia remained unchanged $(\mathrm{r}=-0.76, \mathrm{df}=11$, $p=.004)$, but not in the right $(\mathrm{r}=-0.41, \mathrm{df}=11, p=$ .19). The negative correlation between the $\mathrm{Cr}+\mathrm{PCr} /$ Cho ratios and the scores on the BPRS subscale for positive symptoms also remained significant in the right basal ganglia $(\mathrm{r}=-0.75, \mathrm{df}=11, p=.005)$, but fell just outside conventional level of significance in the left basal ganglia $(\mathrm{r}=-0.56 \mathrm{df}=11, p=.058)$. Given that greater duration of methamphetamine use may correlate with an increased age, there is a possibility that the 
Table 1. Demographic Characteristics of Methamphetamine Users and Comparison subjects

\begin{tabular}{lccc}
\hline & $\begin{array}{c}\text { Methamphetamine } \\
\text { users } \\
(\mathbf{n}=\mathbf{1 3})\end{array}$ & $\begin{array}{c}\text { Comparison } \\
\text { subjects } \\
\text { (n = 11) }\end{array}$ & Significance \\
\hline Age (years) & $25.7 \pm 3.7$ & $26.0 \pm 2.0$ & $\mathrm{NS}$ \\
Gender (Male/Female) & $8 / 5$ & - & $\mathrm{NS}$ \\
Duration of use (years) & $3.2 \pm 2.5$ & - & - \\
Duration of abstinence (years) & $1.5 \pm 1.2$ & - \\
BPRS total score & $7.4 \pm 6.2$ & - \\
BPRS positive symptom subscale score & $4.9 \pm 3.4$ & & - \\
\hline
\end{tabular}

Data are represented as mean $\pm \mathrm{SD}$.

correlation between the $\mathrm{Cr}+\mathrm{PCr} / \mathrm{Cho}$ ratio and the duration of methamphetamine use could be accounted for by the age effect. However, following adjustment for age in a regression model, the significant negative correlations in both the left and right basal ganglia were retained (left: $p=.006$; right: $p=.035$ ). There was no significant correlation between the values of $\mathrm{Cr}+\mathrm{PCr} / \mathrm{Cho}$ ratios and the total BPRS scores in either the left or right basal ganglia (left: $\mathrm{r}=-0.51, \mathrm{df}=12, p=.07$; right: $\mathrm{r}=$ $-0.53, \mathrm{df}=12, p=.06)$.

\section{DISCUSSION}

In ${ }^{1} \mathrm{H}$ MRS studies, the particular method of quantitation is important for interpretation of the results. Relative methods have generally used the cell $\mathrm{Cr}+\mathrm{PCr}$ signal as a reference (Frahm et al. 1989; Davanzo et al. 2001), but this technique has the disadvantage of not definitively distinguishing between the numerator and denominator metabolite changes. Absolute quantitation methods are more accurate in this respect (Ernst et al. 1993; Kreis et al. 1993; Longo et al. 1995). However, at

Table 2. Metabolic Ratios in the Left and Right Basal Ganglia of Methamphetamine Users $(n=13)$ and Comparison Subjects $(\mathrm{n}=11)$

\begin{tabular}{|c|c|c|c|}
\hline & $\mathrm{NAA} / \mathrm{Cr}+\mathbf{P C r}$ & NAA/Cho & $\mathrm{Cr}+\mathrm{PCr} / \mathrm{Cho}$ \\
\hline \multicolumn{4}{|c|}{$\begin{array}{l}\text { Methamphetamine } \\
\text { users }\end{array}$} \\
\hline $\begin{array}{r}\text { Left basal } \\
\text { ganglia }\end{array}$ & $1.38 \pm 0.13$ & $1.79 \pm 0.26$ & $1.29 \pm 0.16$ \\
\hline $\begin{array}{c}\text { Right basa } \\
\text { ganglia }\end{array}$ & $1.44 \pm 0.09$ & $1.78 \pm 0.23$ & $1.22 \pm 0.12$ \\
\hline $\begin{array}{r}\text { Comparison } \\
\text { subjects }\end{array}$ & & & \\
\hline $\begin{array}{r}\text { Left basal } \\
\text { ganglia }\end{array}$ & $1.32 \pm 0.19$ & $1.86 \pm 0.23$ & $1.42 \pm 0.10$ \\
\hline $\begin{array}{l}\text { Right basal } \\
\text { ganglia }\end{array}$ & $1.43 \pm 0.17$ & $1.98 \pm 0.25$ & $1.41 \pm 0.12$ \\
\hline
\end{tabular}

$\mathrm{NAA}=\mathrm{N}$-acetylaspartate. $\mathrm{Cr}+\mathrm{PCr}=$ creatine plus phosphocreatine. Cho $=$ choline-containing compound .

Data are presented as mean \pm SD. the time of this study we were unable to measure metabolites quantitatively.

The present results show that the ratio of $\mathrm{Cr}+\mathrm{PCr} /$ Cho in the bilateral basal ganglia of methamphetamine users was significantly lower than that of comparison subjects. The $\mathrm{Cr}+\mathrm{PCr} / \mathrm{Cho}$ ratios for the bilateral basal ganglia decreased more profoundly with a longer duration of methamphetamine use, suggesting that the longer the use of methamphetamine, the more severe its metabolite alterations. This is congruent with previous studies showing that the neuronal damage (i.e., decreases in NAA and dopamine transporters) caused by methamphetamine is dose-dependent (Villemagne et al. 1998; Ernst et al. 2000; Kim et al. 2000).

The positive symptoms subscale score on the BPRS increased significantly with decreasing $\mathrm{Cr}+\mathrm{PCr} / \mathrm{Cho}$ ratios in the bilateral basal ganglia. Detoxification from methamphetamine in all users was confirmed by regular urine drug screening tests, including a test on the day of the ${ }^{1} \mathrm{H}$ MRS examination, to establish that the psychiatric symptoms evaluated in this study were residual rather than acute symptoms induced by methamphetamine reuse. In fact, the duration of abstinence in our patients ranged from four months to four years, yet their psychiatric symptoms remained persistent after cessation of the use.

Previously, Ernst and his colleagues have shown that the concentration of $\mathrm{Cr}+\mathrm{PCr}$ was decreased in the basal ganglia of methamphetamine users and no change in the concentration of Cho was observed (Ernst et al. 2000). Consequently, the reduced $\mathrm{Cr}+\mathrm{PCr} / \mathrm{Cho}$ found in this study is consistent to be due to a decrease in the $\mathrm{Cr}+\mathrm{PCr}$ level. Therefore, habitual methamphetamine use is thought to induce a reduction in the concentration of $\mathrm{Cr}+\mathrm{PCr}$ in the basal ganglia, which may be related with the pathogenesis of residual psychiatric symptoms in methamphetamine users. In addition, a rather strong correlation was observed on the right side as compared with that on the left side with respect to positive symptoms (see the lower panels in Figure 3). It is of interest to note that lateralized dysfunction has been noted in psychiatric illnesses such as schizophrenia and mood disorder (Lohr and Caligiuri 1997). Fur- 

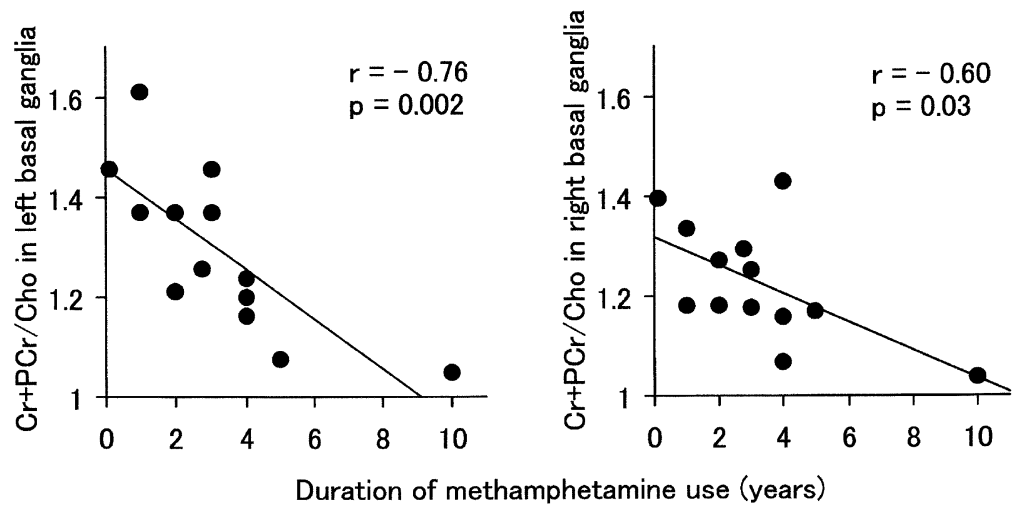

Duration of methamphetamine use (years)
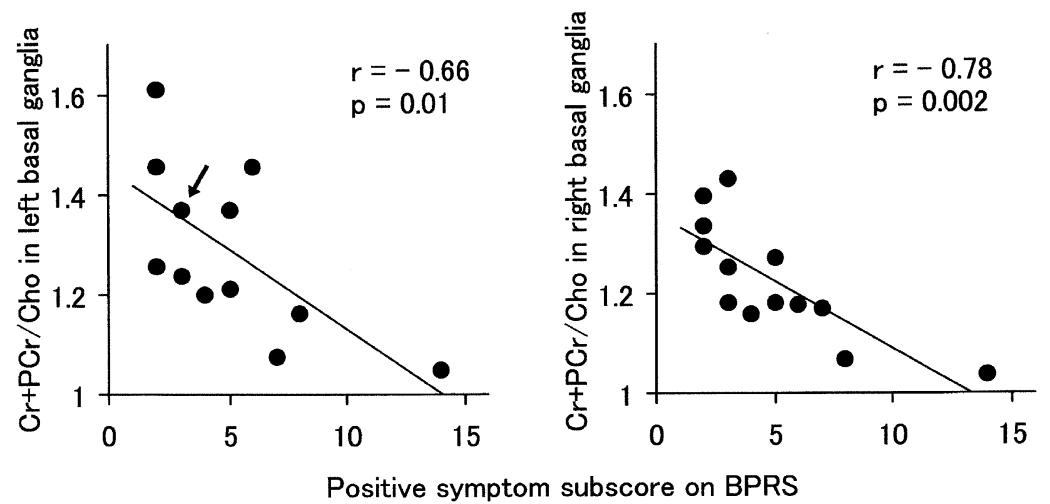

Figure 3. Correlation between clinical variables and values of $\mathrm{Cr}+\mathrm{PCr} / \mathrm{Cho}$ ratio in the left and right basal ganglia of methamphetamine users $(n=13)$. Two subjects had overlapping values, indicated by an arrow. thermore, Volkow and colleagues reported that the right striato-orbitofrontal abnormalities are associated with the craving in addicted individuals (Volkow et al. 1999). Taken together, the positive symptoms in methamphetamine users may be related to metabolite alterations in the right basal ganglia.

The phosphocreatine-creatine equilibrium reaction acts as a reserve for high energy phosphates and buffers cellular ATP/ADP ratios (Miller 1991; Stockler et al. 1996). The $\mathrm{Cr}+\mathrm{PCr}$ signal thus reflects the state of systemic energy use and storage (Stockler et al. 1996; Valenzuela and Sachdev 2001). The reduction in $\mathrm{Cr}+\mathrm{PCr}$ is, in effect, considered to be associated with cellular energy impairment (Hoang et al. 1998; SanchezPernaute et al. 1999).

Previous studies of rodents and dopaminergic neuronal cultures have shown that amphetamine causes neuronal energy impairment. In rodents, methamphetamine has been shown to decrease cytochrome oxidase activity and ATP levels in the striatum (Chan et al. 1994; Burrows et al. 2000). These effects of methamphetamine are selective for dopamine-rich regions, i.e., the striatum and nucleus accumbens. In a study with dopaminergic neuronal cultures, amphetamine has been found to induce mitochondrial dysfunction, which is postulated to predispose dopamine neurons to injury (Lotharius and O'Malley 2001).
Provided that these results extrapolate to humans, it is possible that energy impairment may occur in the basal ganglia of habitual methamphetamine users, resulting in decreased $\mathrm{Cr}+\mathrm{PCr}$ concentration. In fact, Ernst et al. (2000) reported that in methamphetamine users, the concentration of $\mathrm{Cr}+\mathrm{PCr}$ was reduced significantly in the basal ganglia, but not in the frontal cortex or frontal white matter, compared to non-users. This observation is consistent with the results of previous studies, showing that the energy impairment caused by methamphetamine is localized to dopamine-rich regions (Chan et al. 1994; Burrows et al. 2000). Therefore, the neuronal energy impairment in the basal ganglia might participate in the pathogenesis of residual psychiatric symptoms in methamphetamine users.

However, methamphetamine-induced inhibition of mitochondria function in rats, reported by Burrows and colleagues, is rapid and transient (Burrows et al. 2000). It is unclear therefore that this transient change really correlates well with long-term metabolite alterations in abstinent methamphetamine users.

It is well accepted that NAA provides a measure of neurotoxic effects, since its decrease indicates reduced neuronal density or neuronal content (Chang et al. 1999; Ernst et al. 2000). However, in this study, there was no significant difference in the NAA/Cr+PCr or NAA/Cho between the methamphetamine users and 
comparison subjects. One possible explanation for the negative finding in the NAA/Cr+PCr ratio is that decrements in $\mathrm{Cr}+\mathrm{PCr}$ and NAA may concur in methamphetamine users, and hence the ratio of these elements, when compared with that for healthy subjects, might show no difference. While the $\mathrm{Cr}+\mathrm{PCr} / \mathrm{Cho}$ ratio in methamphetamine users was significantly correlated with some clinical characteristics, the ratio of either $\mathrm{NAA} / \mathrm{Cr}+\mathrm{PCr}$ or NAA/Cho in the basal ganglia was not significantly correlated with any of the clinical variables. This suggests that in the case of methamphetamine users, the metabolite changes indicated by $\mathrm{Cr}+\mathrm{PCr} / \mathrm{Cho}$ appear to have more sensitive predictive value for the development of psychiatric symptoms compared with neurotoxic changes indicated by NAA/ $\mathrm{Cr}+\mathrm{PCr}$ or NAA/Cho. In order to clarify the neurotoxic effects (i.e., a decrease in NAA) of methamphetamine on the basal ganglia and possible resulting psychiatric symptoms, a larger scale study will be needed, along with the absolute quantitation methods that allow more accurate metabolite changes to be detected.

Recently, using PET, we found a significant decrease in dopamine transporters in the brain of methamphetamine users, and this reduction was significantly correlated with the duration of methamphetamine use and the scores on BPRS (Sekine et al. 2001). The changes in $\mathrm{Cr}+\mathrm{PCr}$ observed in this study were closely related to the same clinical parameters as in our previous PET study. Therefore, it may well be that the decreases in $\mathrm{Cr}+\mathrm{PCr}$ and dopamine transporters may represent a concurrent process caused by methamphetamine. However, it is unknown whether the change in $\mathrm{Cr}+\mathrm{PCr}$ correlates with the change of dopamine transporters. Therefore, it is necessary to examine these two parameters within individual patients in future studies.

As previously described, two of the methamphetamine users in this study had a history of neuroleptic treatment for methamphetamine-induced psychosis. However, the $\mathrm{Cr}+\mathrm{PCr}$ ratio in the basal ganglia of 11 methamphetamine users without prior medication exposure was significantly reduced compared with control subjects $(\mathrm{F}=5.86, \mathrm{df}=1,20, p=.025)$. The $\mathrm{Cr}+\mathrm{PCr} / \mathrm{Cho}$ ratios in the bilateral basal ganglia were significantly inversely correlated with the duration of methamphetamine use (left: $\mathrm{r}=-0.76, \mathrm{df}=10, p=$ .007 ; right: $\mathrm{r}=-0.70, \mathrm{df}=10, p=.016)$ and with the severity of positive symptoms (left: $\mathrm{r}=-0.61, \mathrm{df}=10, p=$ .048 ; right: $\mathrm{r}=-0.80, \mathrm{df}=10, p=.003$ ). Furthermore, a recent animal study with ${ }^{1} \mathrm{H}$ MRS demonstrated that antipsychotic medications do not alter the Cho/ $\mathrm{Cr}+\mathrm{PCr}$ ratio (Lindquist et al. 2000). Therefore, it is unlikely that the $\mathrm{Cr}+\mathrm{PCr}$ reduction observed in the basal ganglia is an effect of prior medication exposure.

One may raise the possibility that changes in the $\mathrm{Cr}+\mathrm{PCr} / \mathrm{Cho}$ ratio are due to changes in Cho rather than $\mathrm{Cr}+\mathrm{PCr}$. In rodents, methamphetamine adminis- tration has been shown to increase glial cells (Hess et al. 1990; Pu and Vorhees 1993), and the increased levels of Cho are found in glial cells (Urenjak et al. 1993). Therefore, the decrease in $\mathrm{Cr}+\mathrm{PCr} / \mathrm{Cho}$ could be accounted by the elevated Cho level in methamphetamine users. Furthermore, Christensen and colleagues have reported that in humans, acute cocaine administration is associated with a transient increase in the intensity of Cho in the basal ganglia, and with a slight but nonsignificant increase in the $\mathrm{Cr}+\mathrm{PCr}$ peak area (Christensen et al. 2000). However, the aforementioned observations may be specific to cocaine, and it is unclear whether such changes are present in those individuals with long-term exposure to cocaine. Further work is required to address these issues.

We cannot rule out the possibility that the lower levels of $\mathrm{Cr}+\mathrm{PCr} / \mathrm{Cho}$ in methamphetamine users could reflect a behavioral trait liable to chronic drug usage, that is, a genetically determined "addictive personality" induced by intrinsic biochemical abnormalities may be the underlying basis of the neurochemical alterations (van den Bree et al. 1998; Comings and Blum 2000). The partial volume effects of the different regions on the signals may not have been completely averted, since the basal ganglia are typically asymmetric (Watkins et al. 2001). However, such a measurement error would equally affect the patient and comparison subjects (i.e., nondifferential effects) and thus would have biased the results toward the null hypothesis.

In summary, we found a significantly reduced $\mathrm{Cr}+\mathrm{PCr} / \mathrm{Cho}$ ratio in the left and right basal ganglia in methamphetamine users compared with healthy control subjects. Furthermore, the reduction in the $\mathrm{Cr}+\mathrm{PCr} / \mathrm{Cho}$ ratio was significantly correlated with the duration of methamphetamine use and with the severity of residual psychiatric symptoms. These findings suggest that the protracted use of methamphetamine may lead to metabolite alterations in the basal ganglia, which are in turn associated with the generation and persistency of psychiatric symptoms in abstinent users. Additional studies are required to support our view that residual psychiatric symptoms in methamphetamine users might be attributable to the metabolite alterations in the basal ganglia induced by chronic methamphetamine use.

\section{ACKNOWLEDGMENTS}

This work was supported by a Grant-in-Aid for Encouragement of Young Scientists from the Ministry of Education, Culture, Sports, Science and Technology of Japan, a grant for Scientific Research from the Ministry of Health and Welfare of Japan, a grant for Target-Oriented Research and Development from the Ministry of Science and Technology of Japan, and the Stanley Foundation.

We gratefully acknowledge the excellent technical assistance provided by Mr. Hiroyasu Takeda. 


\section{REFERENCES}

Baberg HT, Nelesen RA, Dimsdale JE (1996): Amphetamine use: return of an old scourge in a consultation psychiatry setting. Am J Psychiatry 153:789-793

Buffenstein A, Heaster J, Ko P (1999): Chronic psychotic illness from methamphetamine [letter]. Am J Psychiatry 156:662

Burrows KB, Gudelsky G, Yamamoto BK (2000): Rapid and transient inhibition of mitochondrial function following methamphetamine or 3,4-methylenedioxymethamphetamine administration. Eur J Pharmacol 398:11-18

Chan P, Di Monte DA, Luo JJ, DeLanney LE, Irwin I, Langston JW (1994): Rapid ATP loss caused by methamphetamine in the mouse striatum: relationship between energy impairment and dopaminergic neurotoxicity. J Neurochem 62:2484-2487

Chang L, Ernst T, Strickland T, Mehringer CM (1999): Gender effects on persistent cerebral metabolite changes in the frontal lobes of abstinent cocaine users. Am J Psychiatry 156:716-722

Christensen JD, Kaufman MJ, Frederick B, Rose SL, Moore CM, Lukas SE, Mendelson JH, Cohen BM, Renshaw PF (2000): Proton magnetic resonance spectroscopy of human basal ganglia: response to cocaine administration. Biol Psychiatry 48:685-692

Comings DE, Blum K (2000): Reward deficiency syndrome: genetic aspects of behavioral disorders. Prog Brain Res 126:325-341

Daniels DL, Haughton VM, Naidich TP (1987): Cranial and Spinal MRI: An Atlas and Guide. New York, Raven Press

Davanzo P, Thomas MA, Yue K, Oshiro T, Belin T, Strober M, McCracken J (2001): Decreased anterior cingulate myo-inositol/creatine spectroscopy resonance with lithium treatment in children with bipolar disorder. Neuropsychopharmacology 24:359-369

Ernst T, Kreis R, Ross BD (1993): Absolute quantitation of water and metabolites in human brain. I. Compartments and water. J Magn Reson B 102:1-8

Ernst T, Chang L, Leonido-Yee M, Speck O (2000): Evidence for long-term neurotoxicity associated with methamphetamine abuse: A $1 \mathrm{H}$ MRS study. Neurology 54: 1344-1349

First MB, Spitzer RL, Gibbon M, Williams JB (1996): Structured Clinical Interview for DSM-IV Axis I Disorders (SCID), Non Patient Version. New York State Psychiatric Institute, New York, Biometrics Research

Frahm J, Bruhn H, Gyngell ML, Merboldt KD, Hanicke W, Sauter R (1989): Localized proton NMR spectroscopy in different regions of the human brain in vivo. Relaxation times and concentrations of cerebral metabolites. Magn Reson Med 11:47-63

Hess A, Desiderio C, McAuliffe WG (1990): Acute neuropathological changes in the caudate nucleus caused by MPTP and methamphetamine: immunohistochemical studies. J Neurocytol 19:338-342

Hoang TQ, Bluml S, Dubowitz DJ, Moats R, Kopyov O, Jacques D, Ross BD (1998): Quantitative proton-decoupled 31P MRS and 1H MRS in the evaluation of Huntington's and Parkinson's diseases. Neurology 50:1033-1040
Iwanami A, Sugiyama A, Kuroki N, Toda S, Kato N, Nakatani Y, Horita N, Kaneko T (1994): Patients with methamphetamine psychosis admitted to a psychiatric hospital in Japan. A preliminary report. Acta Psychiatr Scand 89:428-432

Iyo M, Sekine Y, Matsunaga T, Tsukamoto T, Takei N, Mori N (1999): Methamphetamine-associated obsessional symptoms and effective risperidone treatment: a case report (letter). J Clin Psychiatry 60:337-338

Jackson EF (1992): In vivo magnetic resonance spectroscopy in humans: a brief review. Am J Physiol Imaging 7:146154

Kim S, Westphalen R, Callahan B, Hatzidimitriou G, Yuan J, Ricaurte GA (2000): Toward development of an in vitro model of methamphetamine-induced dopamine nerve terminal toxicity. J Pharmacol Exp Ther 293:625-633

Kokoshka JM, Metzger RR, Wilkins DG, Gibb JW, Hanson GR, Fleckenstein AE (1998): Methamphetamine treatment rapidly inhibits serotonin, but not glutamate, transporters in rat brain. Brain Res 799:78-83

Kreis R, Farrow N, Ross BD (1991): Localized 1H NMR spectroscopy in patients with chronic hepatic encephalopathy. Analysis of changes in cerebral glutamine, choline and inositols. NMR Biomed 4:109-116

Kreis R, Ernst T, Ross BD (1993): Absolute quantitation of water and metabolites in human brain. II. Metabolite concentrations. J Magn Reson B 102:9-19

Lindquist DM, Hawk RM, Karson CN, Komoroski RA (2000): Effects of antipsychotic drugs on metabolite ratios in rat brain in vivo. Magn Reson Med 43:355-358

Lohr JB, Caligiuri MP (1997): Lateralized hemispheric dysfunction in the major psychotic disorders: historical perspectives and findings from a study of motor asymmetry in older patients. Schizophr Res 27:191-198

Longo R, Bampo A, Vidimari R, Magnaldi S, Giorgini A (1995): Absolute quantitation of brain $1 \mathrm{H}$ nuclear magnetic resonance spectra. Comparison of different approaches. Invest Radiol 30:199-203

Lotharius J, O'Malley KL (2001): Role of mitochondrial dysfunction and dopamine-dependent oxidative stress in amphetamine-induced toxicity. Ann Neurol 49:79-89

McCann UD, Wong DF, Yokoi F, Villemagne V, Dannals RF, Ricaurte GA (1998): Reduced striatal dopamine transporter density in abstinent methamphetamine and methcathinone users: evidence from positron emission tomography studies with [11C]WIN-35,428. J Neurosci 18:8417-8422

Miller BL (1991): A review of chemical issues in 1H NMR spectroscopy: N-acetyl-L-aspartate, creatine and choline. NMR Biomed 4:47-52

Mohr P, Horacek J, Motlova L, Libiger J, Czobor P (1998): Prolactin response to D-fenfluramine challenge test as a predictor of treatment response to haloperidol in acute schizophrenia. Schizophr Res 30:91-99

Nakayama M, Koyama T, Yamashita I (1993): Long-lasting decrease in dopamine uptake sites following repeated administration of methamphetamine in the rat striatum. Brain Res 601:209-212

Overall JE, Gorham DR (1962): The Brief Psychiatric Rating Scale. Psychol Rep 10:799-812 
Pu C, Vorhees CV (1993): Developmental dissociation of methamphetamine-induced depletion of dopaminergic terminals and astrocyte reaction in rat striatum. Brain Res Dev Brain Res 72:325-328

Sanchez-Pernaute R, Garcia-Segura JM, del Barrio Alba A, Viano J, de Yebenes JG (1999): Clinical correlation of striatal 1H MRS changes in Huntington's disease. Neurology 53:806-812

Sato M, Numachi Y, Hamamura T (1992): Relapse of paranoid psychotic state in methamphetamine model of schizophrenia. Schizophr Bull 18:115-122

Seivewright N (2000): Disorders relating to the use of amphetamine and cocaine. In Gelder MG, Lopez-Ibor JJ, Andreasen N (eds), New Oxford Textbook of Psychiatry. New York, Oxford University Press, pp 531-534

Sekine Y, Iyo M, Ouchi Y, Matsunaga T, Tsukada H, Okada $\mathrm{H}$, Yoshikawa E, Futatsubashi M, Takei N, Mori N (2001): Methamphetamine-related psychiatric symptoms and reduced brain dopamine transporters studied with PET. Am J Psychiatry 158:1206-1214

Shaw KP (1999): Human methamphetamine-related fatalities in Taiwan during 1991-1996. J Forensic Sci 44:27-31

Stockler S, Hanefeld F, Frahm J (1996): Creatine replacement therapy in guanidinoacetate methyltransferase deficiency, a novel inborn error of metabolism. Lancet 348:789-790

Urenjak J, Williams SR, Gadian DG, Noble M (1993): Proton nuclear magnetic resonance spectroscopy unambiguously identifies different neural cell types. J Neurosci 13:981-989

van den Bree MB, Svikis DS, Pickens RW (1998): Genetic influences in antisocial personality and drug use disorders. Drug Alcohol Depend 49:177-187
Valenzuela MJ, Sachdev P (2001): Magnetic resonance spectroscopy in AD. Neurology 56:592-598

Villemagne V, Yuan J, Wong DF, Dannals RF, Hatzidimitriou G, Mathews WB, Ravert HT, Musachio J, McCann UD, Ricaurte GA (1998): Brain dopamine neurotoxicity in baboons treated with doses of methamphetamine comparable to those recreationally abused by humans: evidence from [11C]WIN-35,428 positron emission tomography studies and direct in vitro determinations. J Neurosci 18:419-427

Volkow ND, Wang GJ, Fowler JS, Hitzemann R, Angrist B, Gatley SJ, Logan J, Ding YS, Pappas N (1999): Association of methylphenidate-induced craving with changes in right striato-orbitofrontal metabolism in cocaine abusers: implications in addiction. Am J Psychiatry 156:19-26

Volkow ND, Chang L, Wang GJ, Fowler JS, Leonido-Yee M, Franceschi D, Sedler MJ, Gatley SJ, Hitzemann R, Ding YS, Logan J, Wong C, Miller EN (2001): Association of dopamine transporter reduction with psychomotor impairment in methamphetamine abusers. Am J Psychiatry 158:377-382

Watkins KE, Paus T, Lerch JP, Zijdenbos A, Collins DL, Neelin P, Taylor J, Worsley KJ, Evans AC (2001): Structural asymmetries in the human brain: a voxel-based statistical analysis of 142 MRI scans. Cereb Cortex 11:868-877

Webb PG, Sailasuta N, Kohler SJ, Raidy T, Moats RA, Hurd RE (1994): Automated single-voxel proton MRS: technical development and multisite verification. Magn Reson Med 31:365-373

Woolverton WL, Cervo L, Johanson CE (1984): Effects of repeated methamphetamine administration on methamphetamine self-administration in rhesus monkeys. Pharmacol Biochem Behav 21:737-741 